\title{
Interface: as danças de Ana em Lavoura arcaica ${ }^{1}$
}

\author{
Lúcia Aparecida Martins Campos Coelho* \\ Cristina Martins Coelho** \\ Maria de Lourdes Abreu de Oliveira***
}

\begin{abstract}
Resumo: Este estudo propõe refletir e analisar a representação das danças de Ana em Lavoura arcaica, obra literária de Raduan Nassar e fílmica de Luiz Fernando Carvalho, tendo como um dos principais referenciais teóricos Rudolf Von Laban. Foi possível concluir que na ausência de expressão verbal, Ana canaliza o seu desejo de comunicação em suas danças. Em sua primeira manifestação dançante exibe marcas da tradição e em sua segunda e última dança, os sinais da ruptura.
\end{abstract}

Palavras-chave: Cinema. Dança. Literatura. Lavoura arcaica.

\section{INTRODUÇÃo}

Este ensaio é um estudo de caso cujo objeto é Lavoura arcaica, obra literária de Raduan Nassar (1989), adaptada para o cinema por Luiz Fernando Carvalho (2001). Seu principal objetivo é fazer uma reflexão e uma análise da representação das danças de Ana nestas duas manifestações artísticas, ou seja, tanto no texto original, também denominado de hipotexto literário, quanto no texto originário, também denominado de hipertexto fílmico.

\footnotetext{
*Prefeitura de Juiz de Fora, Juiz de Fora, MG, Brasil. E-mail: lamccoelho@yahoo.com.br

**Faculdade de Educação Física e Desportos. Universidade Federal de Juiz de Fora. Juiz de Fora, MG, Brasil. E-mail: cristina_fisiojf@yahoo.com.br

${ }^{* * *}$ Centro de Ensino Superior de Juiz de Fora. Juiz de Fora, MG, Brasil E-mail: lurabreu@jfa.terra.com.br

${ }^{1}$ Este texto é parte da dissertação de mestrado de Lúcia A. M. C. Coelho, intitulada "A Dança nas Lavouras de Nassar e Carvalho", apresentada em 2009 ao Centro de Ensino Superior de Juiz de Fora, sob orientação da Prof. Dra. Maria de Lourdes Abreu de Oliveira, como requisito para a conclusão do Curso de Mestrado em Letras.
} 
O livro Lavoura arcaica é composto por 30 capítulos que narram, em primeira pessoa, a história de André, um jovem descendente de libaneses que decide abandonar a família devido ao excesso de autoridade do pai e à paixão incestuosa que nutre pela irmã Ana. André é um personagem que manifesta sua revolta através de uma expressão verbal compulsiva; já a irmã Ana, que não verbaliza em momento algum seus sentimentos, fala através da dança. Partindo do princípio de que todo ser humano traz consigo a necessidade de comunicação (LABAN, 1978, 1981, 1990), acredita-se que Ana utiliza-se do corpo como meio de comunicação com o mundo exterior. Acredita-se também que, na ausência de expressão verbal, Ana canaliza o seu desejo de comunicação na exacerbação dos seus movimentos dançantes. Sendo assim, este estudo é norteado pelo seguinte questionamento: Como se efetivou a representação das danças de Ana no hipotexto de Raduan Nassar e no hipertexto de Luiz Fernando Carvalho? Visando responder a tal indagação utilizouse dos estudos de Laban como suporte teórico, articulando-os com os pensamentos de outros estudiosos. É o que será exposto a seguir.

\section{CORPO DIZ O QUE A PALAVRA CALA}

A dança, elemento sempre presente na cultura libanesa, surge em dois momentos no texto literário de Raduan Nassar e no cinematográfico de Luiz Fernando Carvalho. Elas são descritas nos capítulos 5 e 29 do romance Lavoura arcaica e são exibidas no filme, no terceiro capítulo, denominado "Era boa à luz doméstica da nossa infância" e no décimo quinto capítulo, denominado "Foi assim que Ana tomou de assalto a minha festa".

No livro de Raduan Nassar, o narrador-protagonista faz uma descrição detalhada das danças executadas nas reuniões de família, fato que também ocorre no filme de Luiz Fernando Carvalho. A partir da descrição e da exibição dos movimentos realizados pelos membros da família, parentes e amigos, podemos inferir que estes executavam o Dabke, uma dança típica do folclore libanês, enquanto que os movimentos de Ana, personagem central desse estudo, apresentam características e qualidades diferenciadas. 
Utilizando os estudos de Laban (1978, 1981, 1990), principal referencial teórico que norteia esta pesquisa, para caracterizar a qualidade dos movimentos de Ana, temos que, em sua primeira dança, ao se deslocar, descalça, por entre os cestos de frutas de flores, ela realizava com as pontas dos pés movimentos flexíveis, firmes e súbitos, o que equivale à ação básica do talhar. Ana se deslocava sinuosamente, enquanto que com os membros superiores executava, num nível alto, a ação de flutuar, ou seja, ela realizava com os braços movimentos flexíveis, leves e sustentados. Simultaneamente à ação de flutuar, Ana realizava com os dedos das suas mãos, a ação básica de pontuar, isto é, ela estalava os dedos, fazendo uma alusão ao uso das castanholas. Tal movimento caracteriza-se pelo tempo súbito, pelo peso leve e pelo uso do espaço de forma direta.

Dando prosseguimento à descrição da primeira dança de Ana, destacamos que, "magnetizando a todos, ela roubava de repente o lenço branco do bolso de um dos moços, desfraldando-o com a mão erguida acima da cabeça enquanto serpenteava o corpo [...]" (NASSAR, 1989, p. 29). O movimento de desfraldar o lenço acima da cabeça é uma movimentação flexível, firme e súbita, ou seja, o personagem executa com a mão, num nível alto, a ação básica de talhar. Com o resto do corpo, concomitantemente, ela realiza a ação de flutuar, uma vez que o movimento de "serpentear" o corpo é um movimento flexível, leve e sustentado. A movimentação de Ana descrita acima é uma movimentação executada no plano espacial denominado plano da porta e os seus movimentos de braços e mãos são movimentos realizados no nível alto.

Com relação aos movimentos executados por Ana em sua primeira dança, percebemos uma predominância de movimentos flexíveis, demonstrando adaptabilidade, atenção multifocada e menos rigidez do personagem. Observamos também nas descrições de seus movimentos, que eles são, predominantemente, realizados com leveza, revelando suavidade, aceitação e entrega. Quanto ao fator tempo, notamos que, em sua movimentação, mesclam-se movimentos repentinos e lentos, denotando, talvez, um estado interno de desorientação psíquica e emocional. Já quando observamos a fluência 
da movimentação de Ana, percebemos que ela é essencialmente livre e fluente, evidenciando uma sensação de expansão e entrega do personagem à sua dança. Podemos captar, na descrição de Raduan Nassar que, para Ana, dançar é um ato mágico, uma ação capaz de libertá-la temporariamente de suas amarras interiores e deixar vir à tona sua ânsia de vida, alegria e liberdade.

Podemos perceber que, apesar de a descrição das danças de Ana ser praticamente a mesma, a forma como o autor dá início à sua segunda e última dança, os acréscimos feitos a ela e o seu novo desfecho, faz com que ela seja praticamente outra dança, substancialmente diferente da primeira. Nesse ponto é conveniente ressaltar o posicionamento de Laban $(1978,1990)$ com relação à linguagem corporal de um indivíduo. Para esse estudioso, o movimento humano não é uma prática estanque, restrita, uma atividade que possa ser analisada apenas em seus aspectos tangíveis. O movimento é, na verdade, a manifestação do somatório dos aspectos racionais, emocionais, físicos e socioculturais daquele que o realiza.

Desse modo, temos neste momento da narrativa um personagem tomado pela revolta e pela ira, uma mulher disposta a se rebelar contra tudo e todos. Ao se vestir, se exibir e dançar publicamente com as roupas e adereços das prostitutas que André visitou, ao molhar a sua dança e embeber a sua carne de vinho, Ana revelou e assumiu a sua sexualidade, bem como o desejo interdito que nutria pelo irmão. Ana parece dizer para André que está disposta a dar continuidade à paixão proibida. Ela rompe com a pesada tradição imposta pela figura paterna, mudando não apenas o figurino da sua dança, mas também alterando, consideravelmente, a qualidade dos seus movimentos e, consequentemente, o teor do seu discurso corporal.

Os movimentos de Ana, em sua última dança, ganharam mais peso, tornaram-se mais fortes e enérgicos. Sua movimentação ganhou maior rapidez, seus movimentos tornaram-se mais diretos e seu foco principal passou a ser o irmão André, como afirma o próprio 
narrador: "[...] eu estava certo, mais certo do que nunca, de que era para mim, e só para mim, que ela dançava [...]" (NASSAR, 1989, p. 189).

O corpo de Ana, ao se expressar em sua primeira dança, emana não só vida, alegria e sensualidade, mas também manifesta aceitação. Ao modificar a qualidade e a intencionalidade de seus movimentos, ainda que mantenha aparentemente o mesmo gestual, Ana passa a veicular um novo discurso não verbal: o discurso da angústia, do erotismo e da resistência. São os estados internos sendo externamente revelados através dos movimentos. É o corpo que, sinalizando intenções, exibe emoções e atitudes. É o grito desesperado de um corpo desrespeitado e reprimido. É o conflito entre tradição e ruptura se manifestando na linguagem corporal.

A última dança de Ana é uma dança para a morte. Ela parece pressentir seu fim trágico: sua vida ceifada pelas mãos do próprio pai, que, de acordo com o narrador, se sentiu irremediavelmente "ferido nos seus preceitos, que fora possuído de cólera divina (pobre pai!), era o guia, era a tábua solene, era a lei que se incendiava." (NASSAR, 1989, p. 191).

A partir das considerações tecidas acima, percebemos que ao analisarmos as danças em Lavoura arcaica, é necessário que façamos antes algumas considerações mais ampliadas acerca de sua escritura e uma delas diz respeito às festas descritas no romance de Nassar: elas nos remetem ao meio rural. $\mathrm{O}$ escritor usa inúmeros vocábulos relacionados à alimentação, que, associados à dança, nos remetem às antigas celebrações feitas para comemorar a colheita, ou seja, os antigos rituais dionisíacos.

Seria a dança de Ana, em especial a segunda dança, em que ela rouba de um circundante a sua taça de vinho e o derrama sobre os ombros nus, uma alusão aos antigos cultos realizados em homenagem a Dionísio, o deus do vinho, das festas, do lazer, do prazer e da vegetação? André, sempre delirante, contestador, erótico 
e embriagado pelo vinho simbolizaria o próprio Dionísio? E Ana, assim como Lula, seria uma de suas seguidoras?

Como observamos, a dança de Ana dá-nos evidentes indícios de uma linguagem dionisíaca. Para percebermos isto com mais clareza, basta nos reportarmos à história da dança, mais especificamente aos registros feitos em vasos que, segundo Caldeira (2008), registram as danças em homenagem ao deus Dionísio a partir de uma movimentação dinâmica de braços, torso, pescoço e cabeça, acompanhados de passos corridos e de saltos. Na verdade, as danças de Ana nos remetem às bacantes, mulheres que seguiam Baco, o deus do vinho e dos prazeres sexuais, bebendo e dançando compulsivamente, até atingirem o êxtase. Ana parece se identificar com os impulsos dionisíacos do irmão André e expressa isto corporalmente nas festas da família; tempo e espaço das bebidas, comidas e danças.

A rígida disciplina imposta diariamente pelo pai, não só à família, mas também a ele próprio, parece ser abrandada quando este abre as portas de sua lavoura para os parentes e amigos. Isto pode ser inferido a partir do seguinte relato de André: "[...] e eu podia imaginar, depois que o vinho tinha umedecido sua solenidade, a alegria nos olhos do meu pai mais certo então de que nem tudo em um navio se deteriora no porão [...]" (NASSAR, 1989, p. 30).

Nos encontros festivos, com exceção de André, toda a família se manifesta corporalmente, principalmente Ana, que contrastando com os movimentos mais contidos de quase todos os participantes, demonstra total desenvoltura, sensualidade e rejeição às normas vigentes. Nesses momentos, Ana se transforma e é capaz de provocar naqueles que a rodeiam êxtase e entusiasmo. Ela se transforma na mais perfeita sacerdotisa de Baco!

Com relação à movimentação corporal de Ana, de acordo com Rodrigues (2006), há uma grande diferença entre a Ana atraída para a casa velha e recolhida na capela e a Ana presente nas festas. $\mathrm{Na}$ primeira temos uma Ana que se movimenta vagarosamente, avançando e recuando com indecisão, até mesmo uma Ana 
completamente imóvel na capela, caracterizando passividade. Já na segunda temos uma Ana que se movimenta de forma bem mais dinâmica, agitada, uma Ana que transforma passividade em ação. Uma mulher que, rompendo com todas as barreiras, rouba e dança com as quinquilharias da caixa de André, fazendo com que Pedro, sem alternativas, revele ao pai o que o irmão lhe confessara: "Era Ana, era Ana, Pedro, era Ana a minha fome." (RODRIGUES, 2006, p. 129).

Ampliando um pouco mais nossas reflexões sobre as danças e a linguagem corporal de Ana, temos em LavourArcaica um personagem que rompe subitamente o círculo roubando com sua mão direita o lenço branco do bolso de um dos dançarinos. Com os cabelos apanhados do lado por uma flor vermelha, descalça e vestida com um vestido claro e leve, ela nos traz à mente a figura da revolucionária dançarina Isadora Duncan que, libertando-se das sapatilhas e dos figurinos desconfortáveis, subiu ao palco e dançou descalça, trajando apenas uma leve túnica branca. Em sua primeira dança Ana exibe no rosto uma alegria plena e calma e, no corpo, uma sensualidade ingênua de menina moça.

Ana executa movimentos que ora nos remetem à dança do ventre, tais como cambrés, batidas laterais de quadril e de ombros, deslocamentos de cabeça, movimentos ondulatórios de tronco, braços e mãos, além dos giros árabes e das vibrações do corpo, mas realiza também movimentos típicos da dança cigana, do flamenco e do dabke, tais como as batidas fortes e firmes dos pés no chão. É interessante perceber que não encontramos tal relato na narrativa literária; pelo contrário, Nassar (1989, p. 29) afirma que Ana dançava "[...] se deslocando no meio da roda, desenvolvendo com destreza gestos curvos entre frutas, e as flores dos cestos, só tocando a terra na ponta dos pés descalços [...]". Estaria Carvalho com esta interpretação dando mais aterramento, presença e força à movimentação de Ana? Tal como na dança contemporânea que busca demonstrar o peso do corpo indo ao encontro do solo, Ana estaria também, ao bater com firmeza os dois pés no chão, tentando mostrar sua existência real e encontrar seu lugar naquele espaço e 
tempo? Possivelmente sim, uma vez que a narrativa dos gestos só pode ser bem apreendida a partir do conhecimento cultural que os cercam.

Dirigindo agora nosso olhar para a segunda e última dança de Ana exibida no filme LavourArcaica, vemos surgir na tela uma mulher transformada e transtornada. Uma mulher que nos remete à figura da pomba-gira, presente nos rituais umbandistas. A umbanda é uma manifestação religiosa nascida em solo brasileiro, na qual se misturam fortes influências africanas, católicas, kardecistas e até mesmo orientais. Sendo a umbanda uma religião do povo brasileiro, suas entidades representam o retrato social e cultural desse povo. Deste modo, ao lado dos orixás e dos exus encontram-se as figuras de caboclos, boiadeiros, índios, pretos velhos, prostitutas, marinheiros etc. (BARROS, 2006). Ainda segundo esta mesma autora, de todas as divindades da umbanda, os exus são os que mais se assemelham aos homens em termos de paixões, virtude e vícios. Iemanjá é a representação feminina de um orixá e a pomba-gira é a representação feminina de um exu. Nos terreiros de umbanda, Iemanjá é exemplo de grande mãe protetora, ao passo que a pomba-gira é o símbolo da grande cortesã devassa. Os orixás, de acordo com Ortiz (1978), são espíritos de luz e os exus são espíritos das trevas.

A pomba-gira é a síntese dos aspectos mais chocantes que a sexualidade de uma mulher pode assumir e, por isso, ela trabalha na linha esquerda da umbanda, no domínio do mal e da desordem - a quimbanda. A pomba-gira é a personificação do despudor, do que sempre foi oprimido pela moral e bons costumes e que, encarnada, encontra espaço para emergir, transbordar, enfim, revelar-se. A imagem da pomba-gira é a imagem de uma mulher alegre, corajosa, inquieta, rebelde, arrogante e exuberante. Ela é a mais própria expressão do desejo carnal descontrolado, da luxúria e da transgressão das normas, condutas e valores conservadores. Quase sempre sua imagem se liga ao uso de elementos impróprios e proibidos, tais como cigarros, cigarrilhas, cachaça, vinho e champanhe. Assim como Ana se encontra à esquerda na mesa das refeições da família, a pomba-gira também está à esquerda na cultura 
umbandista. Ela não é uma entidade de luz, por isto, é comum ser cultuada em horários e locais marginais, tais como cemitérios, encruzilhadas, cais de portos e matas fechadas.

Ortiz (1978) afirma que, culturalmente, a memória coletiva umbandista também está atrelada aos valores que norteiam a sociedade e que tais valores coincidem com os valores das classes dominantes. A sexualidade é, ainda hoje, um tabu, fonte de mistérios, proibições, pecados e culpas, principalmente no que tange à rigidez religiosa. De acordo com Barros (2006, p. 97), o cristianismo tradicional ainda compreende a mulher de forma dual e antagônica, a saber, a mãe e a pecadora, a virgem e a Messalina, Maria e Madalena. Deste modo, maternidade e sexualidade são aspectos distintos e incompatíveis do feminino.

Os conceitos, preceitos e preconceitos acerca do corpo feminino tiveram suas origens na antiguidade, foram intensificados na Idade Média e mantidos e parcialmente modificados na contemporaneidade. O fato de Deus ser uma figura masculina, a "primogenitura" de Adão e também a crença de que Eva foi formada a partir de uma das costelas de Adão são, segundo Barros (2006, p. 96), concepções decisivas para a formação de um imaginário em que cabe à mulher uma posição de inferioridade e subalternidade em relação ao homem. Sendo assim, parece ser possível inferir que a desvalorização da figura da pomba-gira está vinculada à desvalorização do corpo, em especial à desvalorização do corpo feminino sexuado que ainda permeia nossa cultura.

Apesar de todas as discussões acerca dos direitos femininos, das transformações sociais ocorridas e das conquistas jurídicas, sexuais e psíquicas das mulheres nos últimos tempos, Sohn (2008) nos alerta para não confundirmos a liberação de costumes com a liberação das mulheres, pois a aparente liberação das regras da moral tradicional, oculta, inúmeras vezes, a antiga manipulação das mulheres. "A dominação masculina sabe, portanto, como se renovar e avançar, disfarçada sob a bandeira da liberdade sexual [...]" (SOHN, 2008, p. 154). 
Refletindo um pouco mais sobre atitudes e comportamentos machistas, encontramos na própria obra analisada fortes indícios de discriminação contra a mulher. Temos, por exemplo, além do silêncio das mulheres da família, um irmão que, embora se confesse "louco" pela irmã, se dirige a ela ora com exaltação, ora com julgamentos marcadamente moralistas. Nesses momentos o olhar de André se assemelha aos olhares do pai e de Pedro. Temos também um pai que, transtornado e desesperado diante da tragédia do incesto, opta por tirar a vida da sua filha Ana e não do seu filho André, evidenciando, assim, um pensamento e uma conduta extremamente machistas, frutos de uma cultura de dominação do homem sobre a mulher.

Além das considerações tecidas sobre a discriminação feminina, há ainda na fala do narrador protagonista uma nítida expressão do preconceito que persiste em relação à dança, em especial no que diz respeito à dança praticada pelas mulheres. Percebe-se, claramente, que há na escritura de Nassar (1989, p. 187-188), indícios de um julgamento moralista e preconceituoso relacionado à dança, possivelmente remanescências das concepções de corpo da Idade Média, considerado como fonte de todo o mal, e a dança, expressão do corpo, considerada como uma coisa do demônio.

Segundo Gregersen (1983, p. 179), mesmo com as novas concepções ideológicas de sexualidade dos últimos tempos, a relação da sexualidade com a cultura é ainda bastante complexa, pois que "[...] os aspectos culturais podem modificar-se dramaticamente, porém talvez a cultura da sexualidade seja mais estável do que se suponha." E, sendo assim, infelizmente, ainda paira no imaginário coletivo a concepção de que pura e santa é a esposa, a mãe abnegada e assexuada e, por extensão, pecadora, suja e devassa é a "outra", a mulher que se mostra, impõe e assume a sua sexualidade. E, a partir dessa última concepção, é feita a representação da pomba-gira: uma cortesã, uma mulher corajosa e portadora de uma pulsão sexual desenfreada e ostensiva.

De acordo com Barbosa e Bairrão (2008), a pomba-gira é uma das entidades que mais gosta de se exibir corporalmente e faz isto dançando e se movimentando de maneira muito desinibida e 
extrovertida. Gosta de adornos, maquiagens e roupas ousadas, provocantes e escandalosas, o que acarreta à sua movimentação uma excessiva sensualidade, uma sensualidade tão explícita e irreverente que beira o erotismo. Em sua dança, a pomba-gira exibe sucessivos giros. Ela gira geralmente com um dos pés apoiados inteiramente no chão e o outro apoiado apenas na meia ponta. Manifesta seu prazer de dançar através de sonoras gargalhadas e de uma movimentação voluptuosa de tronco e de cabeça, os quais são geralmente lançados, provocativamente, para trás, num gestual que revela toda a sua ousadia e desejo de enfrentamento. A movimentação corporal da pomba-gira se caracteriza pela liberdade, flexibilidade, além da entrega e aceitação do próprio peso do seu corpo. Ao se deslocar, ela movimenta exageradamente o quadril, criando, a partir deste movimento, um rebolado irreverente e sensual. Por tudo o que foi citado, ela é considerada o maior e mais verdadeiro estereótipo da mulher prostituta e, também por tudo isso, encontramos vários pontos em comum entre a última dança de Ana exibida no filme de Carvalho e a linguagem corporal de uma pomba-gira.

Ainda com relação à obra cinematográfica de Luiz Fernando Carvalho, a trilha sonora utilizada na última dança de Ana é diferente da primeira, assim como outra é a sua dança. Nesta, seus movimentos são caracterizados por extrema voluptuosidade e erotismo. Sua movimentação de cabeça é constante, intensa, desvairada, fazendo com que seus cabelos fiquem em total desalinho, o que nos remete a uma imagem de mulher descontrolada e completamente entregue à loucura. Ana se insinua frequentemente, elevando a saia com as mãos e passando sensualmente seus dedos e mãos pelo rosto e cabelos. Pode-se perceber que ela mantém ainda a flor vermelha, bem como os pés descalços, mas agora traz no corpo as quinquilharias mundanas de André, nas unhas um esmalte vermelho, no rosto uma maquiagem forte, uma expressão por vezes cínica e angustiada, outras vezes de enfrentamento e revolta. E, assim, sua dança se transforma completamente. Ana agora exibe uma nova linguagem corporal. Seus movimentos ganham muito mais energia, vibração e peso. Eles se tornam súbitos, diretos e controlados. Ana executa sucessivos giros, além de repetidas e entrecortadas contrações de 
tronco. Seus movimentos se tornam ainda mais diretos, rápidos e agressivos quando alguém tenta impedi-la de prosseguir com sua dança. Então ela empurra violentamente quem a segura e dá mostras de enfrentamento, ampliando sua cinesfera, talvez na ânsia de ocupação de um maior espaço naquela lavoura. Ao se arremessar ao solo e bater fortemente com as mãos no chão, Ana dá claros indícios de não mais suportar os excessos disciplinares do pai, não suportando também continuar reprimindo suas necessidades e desejos. Em sua última dança, Ana ostenta uma descontrolada sexualidade, ela é a imagem do desatino, da desordem, da revolta, da contestação, do embate, da ruptura e, por fim, da morte.

A segunda dança de Ana é a primeira acrescida do movimento que busca desequilibrar o tradicional e incutir nele o novo. Neste momento ela rompe com a ordem da família. O grito silencioso da dançarina ecoa mais alto e intensamente que a verborragia por vezes alucinada de André. Sem uma palavra sequer é a mulher que age, enquanto o homem fala; é ela que alcança a única alforria possível do estado de coisas vigentes, a única liberdade possível do status quo que a encarcera. É com sua morte que ela cala o mundo que a silencia. Através da dança, Ana consegue o que André não alcança: a quebra, a queda, a ruptura, a destruição da tradição opressora. É imprescindível que Ana morra. Ela não suporta a tradição, tampouco suportaria a nova ordem que busca estabelecer com o irmão.

Enfim, as duas danças de Ana são linguagens. Expressões. Dualidades. Iemanjá e Pomba-gira. Bem e mal. Ordem e desordem. Alegria e angústia. Sensualidade e erotismo. Divino e demoníaco. Aceitação e revolta. Continuidade e ruptura. Vida e morte.

Em torno de Ana um círculo gira. Ao colocar-se no centro do círculo, ela passa a ser, em sua primeira dança, a própria representação do sagrado e, em sua última dança, o símbolo do profano. Na dança de Ana não há lugar para interditos. Enquanto dança, ela comunica-se consigo mesmo e com o outro. Transborda. Supera anseios e manifesta desejos. Sente-se parte de um todo. E 
enquanto gira, gira e gira, entra em transe, esquece-se de si mesma e se entrega à magia do corpo e do movimento. Diz com ele o que a palavra cala.

\section{Considerações FinaIS}

Após estudo comparativo entre as danças descritas no romance Lavoura arcaica e exibidas no filme LavourArcaica, verificamos que na obra cinematográfica foi mantida toda a poesia e lirismo presentes na obra literária. Observamos também que Ana, personagem que não apresenta expressão verbal nas duas obras, manifesta uma representativa linguagem corporal, tanto no hipotexto literário, como no hipertexto fílmico.

Nas lavouras de Nassar e de Carvalho as danças acontecem em dois momentos. No primeiro deles os movimentos de Ana são essencialmente flexíveis, leves, sustentados e livres. Já em sua segunda e última dança, Ana apresenta uma considerável alteração na qualidade de seus movimentos, que ficam mais diretos, firmes, súbitos e controlados. Deste modo, Ana, em sua primeira manifestação dançante, é a expressão da maleabilidade, da suavidade, da tranquilidade e da entrega, enquanto que em sua última dança, Ana revela angústia, rigidez, restrição e resistência. Ainda com relação às danças de Ana, em sua primeira dança, ela é a expressão da vida e da sensualidade e, em sua segunda dança, é a representação da morte e do erotismo.

Tanto no texto de Nassar, quanto no texto de Carvalho, as danças de Ana são linguagens. Linguagens carregadas de significado: na primeira, as marcas da tradição e na segunda, os sinais da ruptura. Apesar de não verbalizar em momento algum, Ana, como nenhum outro personagem, fala e grita com seu corpo. A dança de Ana é o seu verbo! 


\begin{abstract}
Interface: Ana's dances in Lavoura arcaica
Abstract: The aim of the present study was to analyse and reflect on the representations of Ana's dances in Lavoura arcaica, literary and filmic works of Raduan Nassar e Luiz Fernando de Carvalho, respectively, using as the main theoretical reference Rudolf Von Laban. It was possible to conclude that, in the absense of verbal expression, Ana channels her desire of communication into her dances. In her first dancing manifestation, she shows marks of tradition, and in her second and last dance, the signs of rupture.

Keywords: Motion Pictures. Dance. Literature. Lavoura arcaica.
\end{abstract}

\footnotetext{
Interfaz: Las danzas de Ana en Lavoura arcaica Resumen: Este estudio tiene como objetivo reflexionar y analizar la representación de danzas de Ana en Lavoura arcaica, obra literarias de Raduan Nassar, y cinematográfica de Luiz Fernando Carvalho, teniendo como uno de los principales teóricos Rudolf Von Laban. Se concluyó que, en ausencia de la expresión verbal, Ana canaliza su deseo de comunicarse a través de la danza. En su primera manifestación de baile enseña rasgos de la tradición, ya en la segunda y última danza, presenta los signos de ruptura.

Palabras clave: Cinema. Baile. Literatura. Lavoura arcaica.
}

\title{
REFERÊNCIAS
}

BARBOSA, Marielle Kellermann; BAIRRÃO, José Francisco Miguel Henriques. Análise do movimento em rituais umbandistas. Psicologia: Teoria e Pesquisa. Brasília, v. 24, n. 2, p, 225 - 233, abr./jun. 2008.

BARROS, Cristiane Amaral. lemanjá e Pomba-Gira: imagens do feminino na umbanda. 2006. 313 f. Dissertação (Mestrado em Ciências da Religião) Universidade Federal de Juiz de Fora, Juiz de Fora, 2006.

CALDEIRA, Solange Pimentel. A religiosidade na dança: entre o sagrado e o profano. Revista História em Reflexão. Dourados, v. 2, n. 4, p. 1 - 13, jul/dez 2008.

GREGERSEN, Edgar. Práticas sexuais: a história da sexualidade humana. Tradução de Antonio Alberto de Toledo Serra e Edson Ferreira. São Paulo: Livraria Roca, 1983.

Movimento, Porto Alegre, v. 17, n. 03, p. 253-267, jul/set de 2011. 
LABAN, Rudolf. Domínio do movimento. São Paulo: Summus, 1978.

. Man agog: the science of the agogic of movement. The Laban Art of Movement Guild Magazine, London, n.67, nov 1981.

Dança Educativa Moderna. São Paulo: Ícone, 1990.

CARVALHO, Luiz Fernando (Dir). Lavouraarcaica. Direção de fotografia: Walter Carvalho. Trilha sonora: Marco Antônio Guimarães. Produção: Luiz Fernando Carvalho, Maurício Andrade Ramos, Raquel Couto e Tibet Filme. Intérpretes: Selton Mello, Raul Cortez, Juliana Carneiro da Cunha, Simone Spoladore, Leonardo Medeiros e Caio Blat. Belmiro Braga, MG: LFC Produções \& Vídeo Filmes, 2001 (DVD, 163 min, color, son,).

COELHO, Lúcia Aparecida Martins Campos. A dança nas lavouras de Nassar e Carvalho. 2009. 85 f. Dissertação (Mestrado em Letras) - Centro de Ensino Superior de Juiz de Fora, Juiz de Fora, 2009.

NASSAR, Raduan. Lavoura Arcaica. São Paulo: Companhia da Letras, 1989.

ORTIZ, R. A morte branca do feiticeiro negro. Petrópolis: Vozes, 1978.

RAMOS, Rosane Carneiro. A palavra germinada: o grito do romance lírico em Lavoura Arcaica. 2006. 124 f. Dissertação (Mestrado em letras) - Universidade Federal do Rio de Janeiro, Rio de Janeiro, 2006.

RODRIGUES, André Luis. Ritos da Paixão em Lavoura Arcaica. São Paulo: Editora da Universidade de São Paulo, 2006.

SOHN, A. O corpo sexuado. In: CORBIN, A.; COURTINE, J.; VIGARELLO, G. (Dir.). História do corpo: as mutações do olhar: o século XX. Petrópolis: Vozes, 2008. p. 109-154.

Endereço para correspondência:

Lúcia Aparecida Martins Campos Coelho

Endereço: Rua Carlita de Assis Pereira, no30, Bairro Bosque dos Pinheiros, Juiz de Fora, MG CEP: 36062-050

lamccoelho@yahoo.com.br

Recebido em: 08-11-2010

Aprovado em: 28-08-2011 
